cell membrane and the interneuronal axon, possibly at the synaptic zone.

L. A. MARCO

Psychophysiology Laboratory,

Illinois State Psychiatric Institute, Chicago, Illinois.

${ }^{1}$ Renshaw, B., J. Neurophysiol., 4, 167 (1941).

Eccles, J. C., Fatt, P., and Koketsu, K., J. Physiol., 126, 524 (1954).

${ }^{3}$ Eccles, J. C., in The Physiology of Synapses (Academic Press Inc., Publishers, New York, 1964).

'Andersen, P., Eccles, J. C., and Sears, T. A., J. Physiol.,174, 370 (1964)

\section{A Simple Catheter for Intermittent Intravenous Anaesthesia in Animal Surgery}

RECENT allograft experiments on rabbits in our laboratories prompted the development of a simple and safe anaesthetic technique which could be administered by the surgeon to two animals simultaneously. Inhalation techniques require the almost constant attention of another assistant; parenteral barbiturate administration requires repeated and increasingly difficult intravenous injections for maintenance. The following intravenous catheter and continuous technique were therefore devised, based on the standard technique of pentothal induction of anaesthesia in human surgery.

Two No. 25 gauge needles (Yale hypodermic needle, sterile, disposable, No. 25G, 5/8, Becton-Dickinson and Co., Rutherford, New Jersey) and a 12-in. length of polyethylene catheter (Clay-Adams polyethylene tubing, No. PE20, New York) are used. The hub is pulled off and discarded from one needle, and the catheter is swedged on to it, allowing most of the needle to protrude. The other end of the catheter is swedged to the other whole

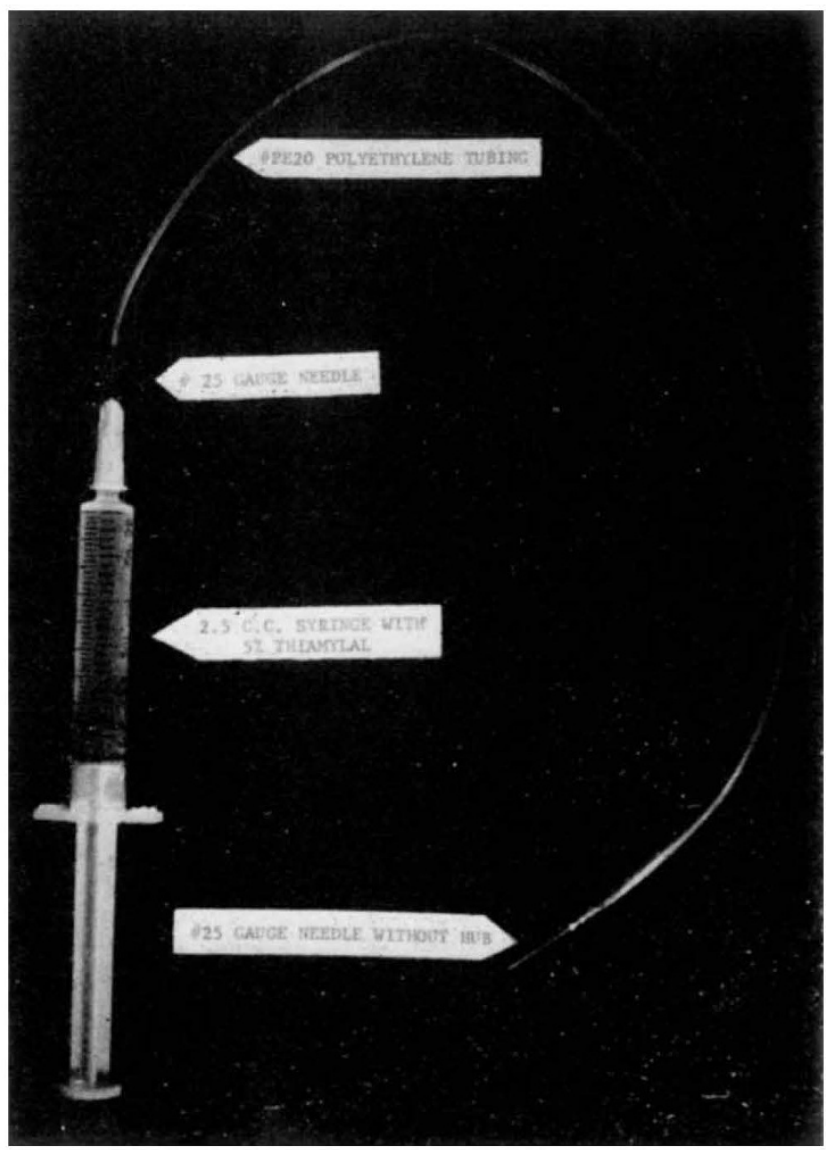

Fig. 1 neodle, or is attached to an adapter (Clay-Adams plastic adapter, No. $A-1025$, size $A$ ). A 2.5-c.e. syringe containing a 5 per cent solution of thiamylal sodium (Surital sodium, Parke-Davis and Co., Detroit, Michigan) is attached.

The distal needle is introduced into an ear vein and taped in place while the rabbit is alert. To induce anaesthesia, $0 \cdot 5-0.8$ c.c. of barbiturate is injected over a period of 30 sec. For maintenance, repeated doses of $0 \cdot 2$ c.e. can be given, usually about every $5-10 \mathrm{~min}$. The taped catheter allows the rabbit's head to move without dislodging the needle; the syringe allows the surgeon himself to maintain satisfactory anaesthetic levols. For sterile procedures, the syringe can be wrapped in a sterile towel or glove in the surgical field.

We have found this technique inexpensive and effective in more than 500 laparotomies and graft exchanges.

This work was partially supported by a grant from the National Institutes of Health, U.S. Public Health Scrvice.

\section{J. F. Hutk A}

Kathleen Mohr

Michael W. LiebermaN

Department of Obstetries and Gynecology, Magee-Women's Hospital, University of Pittsburgh, Pennsylvania.

\section{Blood Volume of the Nasal Salt Glands and other Glands and Organs of Sea Gulls}

THe ability of an organ to function is dependent on its blood supply. The salt gland operates as a highly efficient sodium pump capable of secreting about 8 sodium/adenonine triphosphate ${ }^{1,2}$ and its secretion has a concentration of sodium ranging from 400 to 1,200 m.equiv. sodium chloride/l. (ref. 3). The unique function of the avian salt gland and the lack of information on its blood volume prompted this investigation.

Six sea gulls (Laridae) eaptured along the northern California coast were used. The gulls were maintained in a screened flight cage and given canned dog food to eat and 3 per cent sodium ehloride to drink. Their wing vein was cannulated with a short piece (about 8 in.) of 'Teflon' tubing, A.W.G. No. 22, and $5 \mathrm{ml}$. of blood withdrawn into a heparinized syringe. The blood was ineubated with about $100 \mu \mathrm{c}$. of chromium-51-labolled sodium chromate at $25^{\circ} \mathrm{C}$ for $1 \mathrm{~h}$. The labelled erythrocytes were packed by centrifugation and the supernate discarded. The cells were washed twice in physiological saline by alternately suspending and packing by centrifugation. The erythrocytes were finally resuspended in physiological saline to about their original concentration and injected into the cannulated wing vein. After $15 \mathrm{~min}$ a $1-\mathrm{ml}$. sample of blood was drawn. and the gull was killed by rapidly injecting $2 \mathrm{ml}$. of 6 per cent pentobarbital sodium. The organs were dissected and caro was taken to minimize any contamination of their surfaces with blood or any squeezing of blood from the organ. The haematocrit and radioactivity of triplicate $0 \cdot 1-\mathrm{ml}$. portions of blood were determined using a lead-shielded well-scintillation counter, and the radioactivity per unit volume of whole blood calculated. The whole organ or two representative portions were weighed to the nearest $\mathrm{mg}$, the radioactivity measured with a scintillation counter, and the blood volume calculated.

Of the twelve glands and organs examined, the brain had the lowest blood volume per unit weight, while the lung had the greatest (Table 1). Both right and left salt glands had a blood volume of about $25 \mu \mathrm{l} / \mathrm{g}$, which was comparable with that of the thyroid, adenohypophysis. Harderian gland, pancreas and the pectoralis muscle. However, both the eranial and caudal lobes of the kidney had a blood volume about 4.5 times greater than that of the salt glands. One noticeable reason for this marked 